\title{
Comparison of Performing and Not-Performing the Prophylactic Surgery for Urinary Incontinence in Advanced Pelvic Organ Prolapse
}

\author{
Parvin Bastani $^{1}$, Neda Shoari ${ }^{2}$, Sakineh Haj Ebrahimi ${ }^{3}$, Fatemeh Mallah ${ }^{1}$, Azadeh Azadi ${ }^{2}$
}

\begin{abstract}
Objectives: To compare the Performing and not-performing of prophylactic surgery for urinary incontinence in women with pelvic organ prolapse.

Materials and Methods: In a randomized controlled clinical trial that performed in department of Gynecology and Obstetrics of Tabriz University of Medical Sciences on women with advanced pelvic organ prolapse without history of urinary incontinence. The effects of performing and not-performing of prophylactic surgery for urinary incontinence in women with advance pelvic organ prolapse evaluated.

Results: Mean age of patients was 53.83 \pm 5.52 years in the range of 41-66 years. Mean ICIQ-SF questionnaire scores at the first three questions in patients with pelvic organ prolapse with prophylactic surgery was $0.50 \pm 1.54$ and in patients with pelvic organ prolapse without prophylactic surgery was $0.86 \pm 2.02$. Significant difference was not found at the answers to the first question $(\mathrm{P}=0.507)$, the second question $(\mathrm{P}=0.415)$ and to the third question $(\mathrm{P}=0.445)$ ICIQ-SF questionnaire of in the patients advance pelvic organ prolapse underwent surgery for pelvic organ prolapse with and without prophylactic surgery.

Conclusion: As regards, a significant difference was not found in the prevention of urinary incontinence between groups with and without prophylactic surgery. Therefore, prophylactic surgery is not recommended routinely for all patients and only we will attempt to do this surgery in symptomatic patients and reduced the additional costs and complications associated with prophylactic surgery in other patients who actually did not need to do this surgery.

Keywords: Pelvic Organ Prolapse, Prophylaxis, Urinary Incontinence
\end{abstract}

\section{Introduction}

Pelvic prolapse is the downward and forward movement of a pelvic member towards its natural place and pelvic prolapse is displacement of the bladder, cervix, urethra, or rectum due to defects in pelvic support system. This condition is one of the most common abnormalities among older women. Urogenital prolapse is a common finding in $30 \%$ of women attending gynecologic of outpatient clinic (1-2) and affects up to $50 \%$ of women over 50 years $(1,3)$. Up to $50 \%$ of women who had vaginal delivery suffer from degrees of prolapse, which is symptomatic only at the $20 \%$ of patients $(4,5)$. In a study conducted in 1990 in America, it was reported that vaginal prolapse is the most common indication for hysterectomy in women over 50 (6).

Urethral descent usually is seen with posterior and anterior wall of vagina/enterocele. Common symptoms include urinary frequency, urgency, incontinence, urinary increasing time of urination, feeling of incomplete emptying of the bladder and weak urinary flow. Posterior vaginal wall prolapse symptoms include disposal problems associated with prolonged excretion of urine, feeling of incomplete emptying of the bladder, constipation and fecal discharge with finger (1).

Feeling of something coming down and sexual and urinary symptoms generally described as symptoms of prolapse especially in young women due to inadequacy of urethra (7). Most women with advanced anterior vaginal prolapse do not suffer from incontinency $(1,8)$. Women who have severe pelvic prolapse may also have severe stress urinary incontinence (SUI). Reduction of prolapse during urodynamic assessments reveals non symptomatic cases of SUI in the 36 to $80 \%$ of women with advanced urogenital prolapse $(1,9,10)$.

Some recommend an anti-incontinency preventive procedure with prolapse restoration for prevention of post-operative urinary incontinence, but some do not recommend such a procedure (11-14). For the First time in 1995 Ulmsten and Petros introduced a procedure to support the midsection of urethra without creating tension (15) providing a two-year cure rate of $84 \%$. Since then this method which is named as tension free vaginal tape is used widely. Detayrace and colleagues reported 1

Received 21 May 2014, Revised 9 June 2014, Accepted 25 June 2014, Available online 20 July 2014

${ }^{1}$ Associate Professor of Gynecology and Obstetrics, Women’s Reproductive Health Research Center, Tabriz University of Medical Sciences, Tabriz, Iran. ${ }^{2}$ Resident of Gynecology and Obstetrics, Tabriz University of Medical Sciences, Tabriz, Iran. ${ }^{3}$ Professor of Urology, Tabriz University of Medical Sciences, Tabriz, Iran.

*Corresponding Author: Neda Shoari, Resident of Ob \& Gyn, Tabriz University of Medical Sciences, Tabriz, Iran. E-mail: neda_4622@yahoo.com 
year cure rate of $84 \%$ for this method (16).

In the conducted survey, we found only few studies evaluating the results of preventive surgery for the treatment of urinary incontinence associated with prolapse, with regard to the importance of the prevention of SUI and its treatment, we designed this study to evaluate the results of preventive surgery for urinary incontinency in women with advanced pelvic organs prolapse.

\section{Materials and Methods}

In a controlled randomized trial in the gynecology department of Tabriz University of Medical Sciences on the women suffering the advanced prolapse of pelvic organs the effect of preventive surgery for urinary incontinency was evaluated.

\section{Sample size and Sampling method}

A total number of 60 patients with advanced prolapse of pelvic organs who had no history of urinary incontinency, patients were randomly assigned into two groups, the first group underwent the preventive surgery for urinary incontinency and no intervention was done on the patients in the other group. The results of examinations and ICIQ-SF questionnaires was recorded for all patients before and after the surgery and the follow up was done in order to check the SUI occurrence and the complications by telephone or by attending in the clinic.

\section{Inclusion criteria}

Women with advanced prolapse of pelvic organs without symptoms of urinary incontinency.

\section{Exclusion criteria}

Women with advanced prolapse of pelvic organs with symptoms of urinary incontinency; women who were not candidates for surgery due to illnesses (cardiac, pulmonary, etc.). The variables included age and SUI occurrence after the surgery.

\section{Ethical considerations}

All the diagnosis and treatments were based on the or follow-up and treatment guidelines so it did not impose any additional costs on patients. The patients were ensured that all the data are kept confidential and they were free to leave the study in any time during the study.

\section{Statistical analysis}

We used descriptive analysis (frequency, percent, mean $\pm \mathrm{SD}$ ), and Chi-Square and the mean difference tests for comparing the data between two groups. All the analysis was done using SPSS 16 statistical software. The P value considered meaningful in less than 0.05 .

\section{Results}

The study, conducted on 60 women aged 41 to 66 years with mean age $53.83 \pm 5.52$ years (Figure 1 ).

None of the patients had suffered from urinary incontinence preoperatively. The answers of patients for

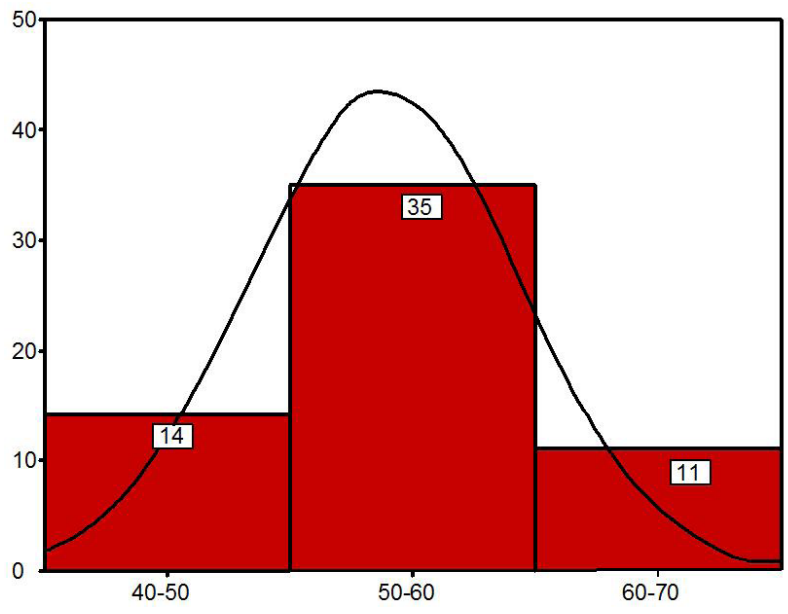

Figure 1. Age distribution of patients

ICIQ-SF questionnaire after pelvic organ prolapse surgery in patients with prophylactic surgery:

First question: How often did you have urine leak?

27 patients (90\%) had no urine leak, 1 patient (3.33\%) had urine leak once a week, and 2 patients $(6.66 \%)$ had urinary leakage 2 or 3 times a week. In 25 patients (83.33\%) patients had no history of urine leak in 4 patients (13.33\%) had urine leak as frequent as once a week and 1 patient (3.33\%) had urine leak 2 or 3 times a week. The difference in the two groups of study (prophylactic surgery group and control group) in response to this question was not statistically significant $(\mathrm{P}=0.507)$.

Second question: How much is the urine leakage?

The response of patients in prophylactic surgery group was: in 27 patients (90\%) no urine leakage, in 1 patient $(3.33 \%)$ mild and in 2 patients (6.66\%) moderate. The response of patients in control group was: in 25 patients (83.33\%) no urine leakage, and in 5 patients $(16.66 \%)$ moderate. The difference in the two groups of study (prophylactic surgery group and control group) in response to this question was not statistically significant $(\mathrm{P}=0.415)$

Third question: In general, how much does urine leakage interfere with your daily life?

The response of patients in prophylactic surgery group was: no interference in 27 (90\%) and 3 patients reported a $20 \%$ interference of urine leakage in their daily lives. In patients without prophylactic surgery: 25 (83.33\%) patients reported no interference, 2 patients $(6.66 \%)$ reported a $10 \%$ interference, 2 patients $(6.66 \%)$ stated a $20 \%$ interference and 1 (3.33\%) estimated the interference of urine leakage as much as $40 \%$.

Pelvic organ prolapse surgery in responding patients without prophylactic surgery in 25 patients (33.83\%) of these patients had urinary leakage does not interfere in any way in their everyday lives, in two cases (6.66\%) interference $10 \%$ of patients, 2 patients $(6.66 \%)$ and in $20 \%$ of cases of interference 1 (3.33\%) of the patients was $40 \%$ interference. Significant differences between 
the results of postoperative pelvic organ prolapse surgery in patients with and without prophylactic surgery in response to the above question, there was no $(\mathrm{P}=0.445)$. The difference in the two groups of study (prophylactic surgery group and control group) in response to this question was not statistically significant $(\mathrm{P}=0.445)$. Mean ICIQ-SF questionnaire responses score in patients with pelvic organ prolapse surgery for the first three questions who undergone prophylactic surgery also was $0.5 \pm 1.54$ and in patients without prophylactic surgery was $0.86 \pm 2.02$ (Figure 2).

Significant difference between the mean total scores on the ICIQ-SF pelvic organ prolapse surgery in patients with the first three questions with and without prophylactic surgery was observed $(\mathrm{P}=0.435)$. There was statistically significant difference in score of 3 first questions between the 2 groups $(\mathrm{P}=0.435)$.

Fourth question: when does urine leakage occur?

The response of patients in prophylactic surgery group was: 27 patients (90\%) never had urinary leakage, 3 cases (10\%) of patients had urine leakage when coughing or sneezing. The response of patients in control group was: 25 patients $(83.33 \%)$ never had urinary leakage, 5 cases (10\%) of patients had urine leakage when coughing or sneezing. There were no cases of complication in two groups of study.

\section{Discussion}

Urinary incontinence is a major health problem throughout the world. In 2000, urinary incontinence was the cause of more than 1.1 million medical visits in the United States, the direct and indirect costs arising from the same year, was over 19.5 million dollars. Risk factors for urinary incontinence include age, vaginal delivery, obesity, menopause, smoking, chronic coughs constipation and pelvic surgery. Urinary incontinence is much more common in women than in men, and its incidence in different studies was 5-72\%.

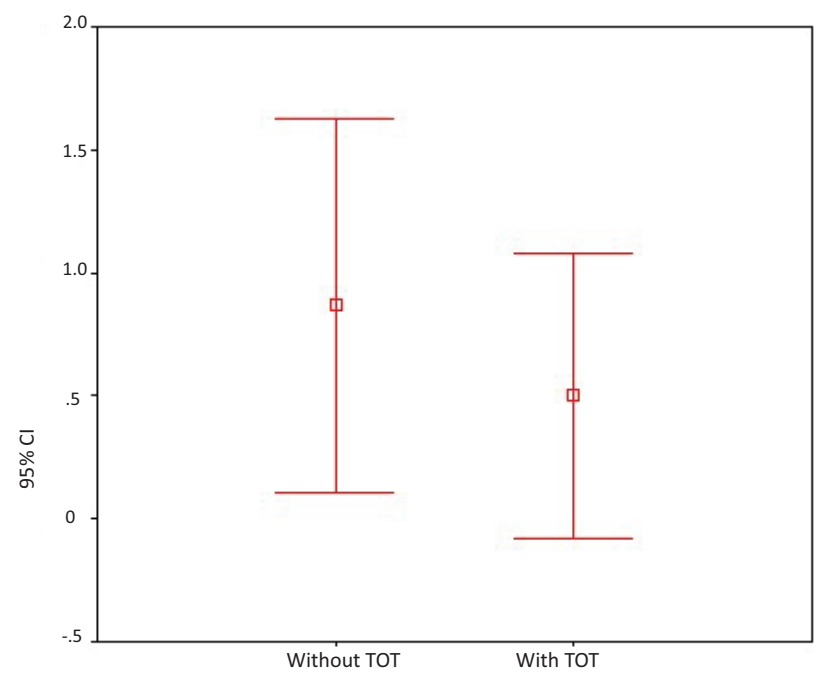

Figure 2. ICIQ-SF score ranges in two groups of patients
Several questionnaires were used for Initial assessment of incontinence including Urogenital Distress Inventory (UDI6) Incontinence impact questionnaire-7, IIQ-7, and Pelvic floor Impact questionnaire short form 7 (17-20). ICIQ is a questionnaire in the form of a six short questions that are written by the International Association of ICI and has been validated by Hajebrahimi et al. (19).

In 2001 a novel technique was introduced by Delorme that reserved the situation and effectiveness of mid urethra in tension-free vaginal tape (TVT) and was free from the complications of intervention in retro pubic area, this method was named trans-obdurate-tape (TOT) (15).

In a prospective study by Juma et al. (17) in 2007, on 130 patients who undergone TOT surgery were followed for 2 years. They examined patients' quality of life with IIQ questionnaire (Incontinence Impact Questionnaire), Urogenital distress inventory (UDI) and analog global satisfaction scale (GSS). Among the 117 patients (90\%) had a history of SUI and 78 patients (60\%) had urgency. Number of pads used per day, before surgery was $2.48 \pm 2.42$, and scores of IIQ, UDI and GSS, was measured $16.13 \pm 7.86,10.95 \pm 3.4$ and $1.41 \pm 1.67$ respectively. The mean time of hospital stay was $0.84 \pm 0.76$ days and duration of urinary catheter placement was $1.42 \pm 2.08$ days. During the postoperative follow-up period, 13 patients (10\%) had recurrent SUI, 21 patients (16.15\%) had optional. After surgery, the number of pads used per day was $0.15 \pm 0.56$, and scores of IIQ, UDI and GSS, respectively, versus $1.47 \pm 5.14,3.28 \pm 3.09$ and $8.29 \pm 1.64$ respectively.

In another study by Porena et al (21) which was conducted on 148 patients to compare TVT and TOT. Patients were divided were randomly into TVT (73 patients) and TOT group (75 patients). UDI and IIQ questionnaire was filled for patients before surgery and one hour pad test were evaluated. Finally, they showed that both of these methods are safe - the risk of complications during and after surgery had no statistically significant difference between the two groups. In the follow-up period (mean 31 months) SUI was reported in $71.4 \%$ in the TVT group and $77.3 \%$ in the TOT group of patients. Average satisfaction level was 9 (range 1-10)

In a study by Ennemoser and colleagues at the Department of Obstetrics and Gynecology, University of Munich, Germany in 2012 on patients with pelvic organ prolapse surgery, the rate of stress incontinence was $28.1 \%$ in the follow-up period which only $5.3 \%$ of the patients required further surgery for incontinence (22).

In our study complained of urinary incontinence in patients with prophylactic surgery in 3 patients $(10 \%)$ were found in patients without prophylactic surgery of urinary incontinence after surgery, 5 patients (16.66\%) were in patients with prophylactic surgery than patients without prophylactic surgery, but this difference was not significant. In our study the rate of complaint for urinary incontinence in patients in prophylactic surgery group was $10 \%$ ( 3 patients) but this rate was $16.66 \%$ (5 patients) in control group, although the SUI was higher in control group, the difference was not significant in two groups. 
In a meta-analysis by Maher et al., on patients with pelvic organs prolapse, it was concluded that, using of Mesh in urinary incontinency surgery can significantly reduce the post-operative urinary incontinency in these patients (1). In another study by Maher and colleagues in 2008 on patients with pelvic organ prolapse, I was stated that TOT can reduce post-operative urinary incontinence in such patients (23).

In our study, like the results of the above study, prophylactic surgery causes a decrease in the rate of urinary incontinence after surgery, but the difference was not statistically significant.

In a study by Withagen and colleagues at the Department of Obstetrics and Gynecology of Nijmegen University on patients with pelvic organ prolapse that underwent the surgery is stated that the surgery is one of the risk factors for urinary incontinence after pelvic surgery in these patients (24).

In a study by Meschia and colleagues at the Department of Obstetrics and Gynecology, University of Milan, Italy in 2004 on patients with pelvic organ prolapse who underwent surgery, it was stated that TOT surgery in women is associated with a clinical reduction of urinary incontinence and it is recommended in these patients (25). Revicky and colleagues have also reported the TOT procedure as an effective method in patients who underwent the pelvic organs prolapse reducing postoperative urinary incontinence (26). Paganotto and colleagues, in Bologna University in Italy reported the TOT as a highly effective method in reducing the postoperative urinary incontinence (27). Matarazzo and colleagues has also found a significant role in reducing the post-operative urinary incontinence (28). Karateke et al. conducted a study in Zeynep Kamil university of Istanbul on the patients with prolapse of pelvic organs, they stated that the urinary incontinency was lower in patients with TOT, but the difference between two groups with and without TOT was not significant (29). In another study by Tsivian on patients with pelvic organs prolapse, it is stated that the simultaneous surgery for TOT and pelvic organs prolapse is an effective method in reducing the post-operative urinary incontinency (30).

Lo and colleagues at the Department of Obstetrics and Gynecology of Chang Gung University, China in 2009 on patients with pelvic prolapse stated that the perform of simultaneous TOT and surgery of pelvic organs prolapse is beneficial and reduces the intensity of urinary incontinence after surgery (31). Ayhan and colleagues in Baskant university of Turkey in 2009 reported a high efficacy for synchronous TOT with surgery of pelvic organ prolapse (32).

As noted in the studies above, performing the prophylactic surgery with pelvic organs surgery is a useful method that reduces the complaints about the post-operative incontinency, in our study the prophylactic surgery has also reduced the post-operative urinary incontinency, but the difference between two intervention and control group was not statistically different, perhaps this can be due to limited number of patients. More multicenter studies is recommended for prove of the efficacy of these procedure.

\section{Conclusion}

As regards, a significant difference was not found in the prevention of urinary incontinence between groups with and without prophylactic surgery. Therefore, prophylactic surgery is not recommended routinely for all patients and only we will attempt to do this surgery in symptomatic patients and reduced the additional costs surgery in cases where the patient is symptomatic. Moreover, reduced of the additional costs and complications associated with prophylactic surgery in other patients who actually did not need to do this surgery.

\section{Ethical issues}

All patients signed an informed consent for attending this study. Approval of the local ethics committee from "Tabriz University of medical sciences Ethics Committee" was taken before the study was begun.

\section{Conflict of interests}

Authors declare that there is no conflict of interest.

\section{Acknowledgments}

We acknowledge the kind personnel of Tabriz Women's Reproductive Health Research center. This study was registered in Iranian clinical trials website (IRCT code: N12013041513025).

\section{References}

1. Maher CM, Feiner B, Baessler K, Glazener CM. Surgical management of pelvic organ prolapse in women: the updated summary version Cochrane review. Int Urogynecol J 2011; 11: 1445-57.

2. Bump RC, Norton PA. Epidemiology and natural history of pelvic floor dysfunction. Obstet Gynecol Clin North Am 1998; 25: 723 -746.

3. Samuelsson EC, Arne Victor FT, Tibblin G, Svardsudd KF. Signs of genital prolapse in a Swedish population of women 20 to 59 years of age and possible related factors. Am J Obstet Gynecol 1999; 180: 299-305.

4. Olsen AL, Smith VJ, Bergstrom JO, Colling JC, Clark AL. Epidemiology of surgically managed pelvic organ prolapse and urinary incontinence.Obstet Gynecol 1997; 89: 501-6.

5. Beck RP, McCormick S, Nordstrom L. A 25-year experience with 519 anterior colporrhaphy procedures. Obstet Gynecol 1991; 78: 1011-8.

6. Wilcox LS, Koonin LM, Pokras R, Strauss LT, Xia Z, Peterson HB. Hysterectomy in the United States.Obstet Gynecol 1994; 4: 549-555.

7. Swift SE, Tate SB, Nicholas J. Correlation of symptoms with degree of pelvic organ support in a general population of women: what is pelvic organ prolapse? Am J Obstet Gynecol 2003; 189: 372-379.

8. Herzog AR, Fultz NH. Prevalence and incidence of urinary incontinence in community-dwelling populations. J Am Geriatr Soc 1990; 3: 273-281. 
9. Bergman A, Koonings PP, Ballard CA. Predicting postoperative urinary incontinence development in women undergoing operation for genitourinary prolapse. Am J Obstet Gynecol 1988; 158: 1171-5.

10. Drutz HP, Alnaif B. Surgical management of pelvic organ prolapse and stress urinary incontinence. Clin Obstet Gynecol 1998; 41: 786-93.

11. Klutke JJ, Ramos S. Urodynamic outcome after surgery for severe prolapse and potential stress incontinence. Am J Obstet Gynecol 2000; 182: 378-81.

12. Colombo M, Maggioni A, Scalambrino S, Vitobello D, Milani R. Surgery for genitourinary prolapse and stress incontinence: a randomized trial of posterior pubourethral ligament plication and Pereyra suspension. Am J Obstet Gynecol, 1997; 76: 337-43.

13. Chaikin DC, Groutz A, Blaivas JG. Predicting the need for antiincontinence surgery in continent women undergoing repair of severe urogenital prolapse. J Urol 2000; 163: 531-4.

14. Ulmsten U, Henriksson L, Johnson P. An ambulatory surgical procedure under local anesthesia for treatment of female urinary incontinence. Int Urogynecol J 1996; 7:81- 6 .

15. Delorme E. Transobturator urethral suspension; a minimally invasive procedure to treat female stress urinary incontinence. ProgUrol 2001; 11:1306-13.

16. deTayrac R, Deffieux X, Droupy S, Chauveaud-Lambling $\mathrm{A}$, Calvanèse-Benamour L, Fernandez $\mathrm{H}$. A prospective randomized trial comparing tension-free vaginal tape and transobturator suburethral tape for surgical treatment of stress urinary incontinence. Am J Obstet Gynecol 2004; 190: 602-8.

17. Juma S, Brito CG. Transobturator Tape (TOT): Two years follow-up. Neurourol Urodyn 2007;26(1):37-41.

18. Espuña-Pons M, Dilla T, Castro D, Carbonell C, Casariego J, Puig-Clota M. Analysis of the value of the ICIQ-UI SF questionnaire and stress test in the differential diagnosis of the type of urinary incontinence. Neurourol Urodyn 2007; 6: 836-41.

19. Hajebrahimi S, Nourizadeh D, Hamedani R, Pezeshki MZ. Validity and reliability of the International Consultation on Incontinence Questionnaire-Urinary Incontinence Short Form and its correlation with urodynamic findings. Urol J 2012; 4: 685-90.

20. Espuña Pons M, Rebollo Alvarez P, Puig Clota M. Validation of the Spanish version of the International Consultation on Incontinence Questionnaire-Short Form. Aquestionnaire for assessing the urinary incontinence. Med Clin (Barc) 2008; 8: 288-92.

21. Porena M, Costantini E, Frea B, Giannantoni A, Ranzoni S, Mearini L, et al. Tension-free vaginal tape versus transobturator tape as surgery for stress urinary incontinence: results of a multicentre randomised trial. Eur Urol 2007; 5: 1481-90.

22. Ennemoser S, Schönfeld M, von Bodungen V, Dian D, Friese K, Jundt K. Clinical relevance of occult stress urinary incontinence (OSUI) following vaginal prolapse surgery: long-term follow-up. Int Urogynecol J 2012; 7: 851-5.

23. Maher C, Baessler K, Glazener CM, Adams EJ, Hagen S. Surgical management of pelvic organ prolapse in women: a short version Cochrane review. Neurourol Urodyn 2008; 1: 3-12.

24. Withagen MI, Milani AL. Which factors influenced the result of a tension free vaginal tape operation in a single teaching hospital? Acta Obstet Gynecol Scand 2007; 9: 1136-9.

25. Meschia M, Pifarotti P, Spennacchio M, Buonaguidi A, Gattei U, Somigliana E. A randomized comparison of tension-free vaginal tape and endopelvic fascia plication in women with genital prolapse and occult stress urinary incontinence. Am J Obstet Gynecol 2004; 3: 609-13.

26. Revicky V, Tincello DG. New surgical approaches for urinary incontinence in women. Maturitas 2014; 3: 23942.

27. Paganotto MC, Amadori L, Di Donato N, Mauloni $\mathrm{M}$, Busacchi P. Use of a preventive sling surgery for the simultaneous correction of latent stress urinary incontinence during the cystocele repair: two year follow-up. Minerva Ginecol 2013; 3319-26.

28. Matarazzo MG, Cianci S, Rampello L, Presti LL, Caruso S. Urethral sphincter innervation and clitoral blood flow after the transobturator (TOT) approach. Int Urogynecol J 2012; 4: 621-5.

29. Karateke A, Tug N, Cam C, Selcuk S, Asoglu MR. Concomitant surgical correction of occult stress urinary incontinence by TOT in patients with pelvic organ prolapse. Eur J Obstet Gynecol Reprod Biol 2011; 1:1057.

30. Tsivian A, Benjamin S, Tsivian M, Rikover M, Mogutin B, Korczak D, et al. Transobturator tape procedure with and without concomitant vaginal surgery. J Urol 2009; 3: 1068-71.

31. Lo TS. Combined pelvic reconstructive surgery and transobturator tape (monarc) in women with advanced prolapse and urodynamic stress incontinence: a case control series. J Minim Invasive Gynecol 2008; 2: 163-8.

32. Ayhan A, Dogan NU, Guven S, Guler OT, Boynukalin FK, Salman MC. Clinical outcome of transobturator tape concomitant with vaginal hysterectomy plus anterior posterior colporrhaphy. Arch Gynecol Obstet 2009; 3: 375-80.

Copyright ( 2014 The Author(s); This is an open-access article distributed under the terms of the Creative Commons Attribution License (http://creativecommons.org/licenses/by/4.0), which permits unrestricted use, distribution, and reproduction in any medium, provided the original work is properly cited. 